\title{
Benefícios fiscais e sustentabilidade: um estudo dos municípios catarinenses
}

\author{
Amery Moisés Nadir Junior 12 \\ Anete Alberton 2 \\ Kleverton Clóvis de Oliveira Saath ${ }^{3}$ \\ ${ }^{1}$ Secretaria da Fazenda de Santa Catarina, Florianópolis / SC - Brasil \\ 2 Universidade do Vale do Itajai / Programa de Pós-Graduação em Administração, Biguaçu / SC - Brasil \\ ${ }^{3}$ Universidade Federal de Santa Catarina, Florianópolis / SC - Brasil
}

\begin{abstract}
A relação entre benefícios fiscais e sustentabilidade não tem sido objeto de muitas pesquisas empíricas, apesar da importância da mensuração e do acompanhamento da efetividade dos gastos tributários. Assim, o objetivo deste artigo é analisar a influência dos benefícios fiscais de ICMS - imposto sobre circulação de mercadorias e prestação de serviços de transporte e de comunicação - na sustentabilidade dos municípios catarinenses. Para tanto, com base num conjunto de dados secundários em painel, coletados entre 2005 e 2017, emprega-se a modelagem de equações estruturais. A despeito de os resultados apontarem relações estatisticamente significativas, constata-se que os benefícios fiscais, em grau elevado, promovem a sustentabilidade econômica; em grau moderado, a sustentabilidade social; e, em grau baixo, a sustentabilidade ambiental.
\end{abstract}

Palavras-chave: benefícios fiscais de ICMS; gastos tributários; municípios; sustentabilidade; triple bottom line.

\section{Beneficios fiscales y sostenibilidad: un estudio en los municipios catarinenses}

La relación entre los beneficios fiscales y la sostenibilidad no ha sido objeto de mucha investigación empírica, a pesar de la importancia de medir y monitorear la efectividad de los gastos tributarios. Por lo tanto, el objetivo de este artículo es analizar la influencia de los beneficios fiscales del ICMS - impuesto sobre la circulación de bienes y la provisión de servicios de transporte y comunicación - sobre la sostenibilidad de los municipios catarinenses. Para ello, con base en un conjunto de datos secundarios en panel, recopilados entre 2005 y 2017, se emplea el modelado de ecuaciones estructurales. Aunque los resultados apuntan a relaciones estadísticamente significativas, parece que los beneficios fiscales, en un alto grado, promueven la sostenibilidad económica; en un grado moderado, la sostenibilidad social; $y$ en un grado bajo, la sostenibilidad ambiental.

Palabras clave: beneficios fiscales de ICMS; gastos tributarios; municipios; sostenibilidad; triple bottom line.

\section{Tax benefits and sustainability: a study of municipalities in the state of Santa Catarina}

The relationship between tax benefits and sustainability is not well explored in empirical research, despite the importance of measuring and monitoring the effectiveness of tax expenditures. This article aims to analyze the influence of the ICMS tax benefits - tax on the circulation of goods and the provision of transport and communication services - on the sustainability of municipalities in the state of Santa Catarina. Structural equation modeling examined a set of secondary panel data collected between 2005 and 2017. Although the results point to statistically significant relationships, it appears that tax benefits promote economic sustainability to a high degree; social sustainability to a moderate degree; and environmental sustainability to a low degree.

Keywords: tax benefits of ICMS; tax expenditure; municipalities; sustainability; triple bottom line. 


\section{INTRODUÇÃO}

A efetividade da política de benefícios fiscais do imposto sobre circulação de mercadorias e prestação de serviços de transporte e de comunicação (ICMS) é um tema recorrente e controvertido, tendo em vista o montante de renúncia fiscal envolvido e a ausência de avaliação periódica, criteriosa e multidimensional dos impactos desses benefícios (Abraham, 2019; Afonso, 2014; Freitas, 2016; Pellegrini, 2014). Todavia, não se deve desprezar os benefícios que as desonerações tributárias podem trazer para o desenvolvimento socioeconômico (Botelho, Abrantes \& Fialho, 2019).

Neste artigo, adota-se o conceito de gasto tributário (tax expenditure), que obteve cientificidade a partir dos estudos de Surrey (1970), no início da década de 1970, para tornar os gastos públicos indiretos mais transparentes, tratando-os, nos orçamentos governamentais, de modo semelhante aos gastos públicos diretos (Lester, 2017; Pellegrini, 2014). Os gastos tributários são uma alternativa aos gastos públicos diretos, sobretudo diante da carência de recursos financeiros para a prestação dos serviços essenciais à população local, os quais são de competência dos governos municipais (Buissa, Bevilacqua \& Morais, 2017; Gomes, Osborne \& Guarnieri, 2020).

É nesse contexto que os benefícios fiscais e a sustentabilidade se unificam, atingindo os municípios, que usufruem (ou suportam) dos efeitos positivos (ou negativos) da atividade produtiva. Assim, a extrafiscalidade tributária se configura como um instrumento de internalização das externalidades e de enfrentamento dos problemas estruturais da sociedade, como injustiças econômicas, pobreza extrema e a persistente degradação do meio ambiente (J. Sachs, 2017; Wedy, 2018). Não obstante, os governos devem adotar políticas tributárias e de gastos ótimas (Kalambokidis, 2014); caso contrário, a proliferação de benefícios fiscais pode corroer as bases tributárias, em especial nos países em desenvolvimento, causando distorções como o favorecimento das importações sobre as compras locais (Caldeira, Geourjon \& Rota-Graziosi, 2020).

Neste artigo, utiliza-se o conceito de triple bottom line (TBL), o qual sintetiza as três principais dimensões da sustentabilidade - prosperidade econômica, justiça social e qualidade ambiental (Elkington, 1998), de maneira balanceada e equitativa (Alhaddi, 2015), fazendo o TBL evoluir para uma proxy do construto sustentabilidade (Isil \& Hernke, 2017). A Agenda 2030 (Organização das Nações Unidas [ONU], 2015) - concebida como um plano mundial de ações para o desenvolvimento sustentável - também se baseia no tripé "prosperidade, pessoas e planeta".

Ademais, verifica-se a carência de estudos sobre o potencial de arrecadação do imposto sobre valor agregado (IVA) - categoria da qual o ICMS, originalmente, descende e à qual pertence (Carrazza, 2015) - e seu impacto nos débitos e no deficit governamentais (Ufier, 2017), bem como em relação às condições nas quais os gastos tributários são mais eficazes (Kasdin, 2018). Além disso, são necessárias mais evidências empíricas a respeito da eficácia dos benefícios fiscais nos países em desenvolvimento (Parys \& James, 2010).

Assim, neste artigo, são analisados os gastos tributários de ICMS em Santa Catarina - compostos dos montantes de renúncia fiscal, apresentados nas Leis de Diretrizes Orçamentárias -, considerando a agressiva política de benefícios fiscais desse estado, especialmente na atração de investimentos e empreendimentos no âmbito da guerra fiscal (Daros \& Secchi, 2013; Macedo \& Angelis, 2013). Por exemplo, em Santa Catarina, o montante estimado de renúncia fiscal de ICMS, em 2019, foi de 5,8 bilhões de reais (Lei no 17.566 , de 7 de agosto de 2019), representando 2,26\% do produto interno bruto (PIB) estadual, $20,5 \%$ da receita orçamentária estadual e $35 \%$ da arrecadação anual com esse imposto. 
Os estudos de Accordino (2020), Chicumbi (2018), He et al. (2019), Klemm e Parys (2012), Parys e James (2010), Porto e Memória (2019), Qi, Peng e Xiong (2020), Rezende, Dalmácio e Rathke (2018), Rezende, Peralta, Rosa e Rezende (2019), bem como Sá e Silva (2019), contudo, apontam que as desonerações tributárias são instrumentos importantes para a atração de investimentos e empreendimentos, assim como para a promoção da sustentabilidade no conceito TBL. Desse modo, com base nesses estudos, parte-se da tese de que os benefícios fiscais de ICMS influenciam, positivamente, na sustentabilidade dos municípios catarinenses.

Esta pesquisa, porém, ao se restringir aos efeitos dos benefícios fiscais concedidos em Santa Catarina, não considera os efeitos das desonerações sobre as demais unidades da federação - como as perdas de arrecadação e distorções na eficiência alocativa de recursos -, considerando que o ICMS é abrangente e dinâmico, com a política tributária de cada estado influenciando diretamente o desenvolvimento dos demais, sobretudo no âmbito da competição tributária, denominada "guerra fiscal" (Brandão, 2014; Nascimento, 2008; Oliveira, 2015; Rezende, 2020).

Por fim, ante o exposto, o artigo tem por objetivo analisar a influência dos benefícios fiscais de ICMS na sustentabilidade econômica, social e ambiental dos atuais 295 municípios catarinenses. Para tanto, emprega-se a técnica de modelagem de equações estruturais, com base numa estrutura de dados secundários em painel, coletados entre 2005 e 2017.

\section{FUNDAMENTAÇÃO TEÓRICA}

A escolha da literatura considerou, além do estado da arte do conhecimento sobre benefícios fiscais e sustentabilidade, em trabalhos nacionais e estrangeiros, as características (singulares) do ICMS, cuja sigla alberga pelo menos cinco impostos diferentes - sobre operações mercantis, sobre serviços de transporte, sobre serviços de comunicação, sobre lubrificantes e combustíveis, sobre minerais (Carrazza, 2015) -, ao contrário de um moderno IVA - vigente em vários países sul-americanos, europeus e asiáticos (Balthazar, 2008) -, que incide de maneira uniforme sobre uma base ampla de bens e serviços (Appy, Santi, Coelho, Machado \& Canado, 2020).

\subsection{Intervenção estatal e gastos tributários}

A partir da Primeira Guerra Mundial, diante das crises econômicas que obrigaram os governos a agir para sanar as falhas de mercado, começou-se a falar em intervenção estatal (Caliendo, 2013; Sunstein, 2014). Hoje em dia, ela pode e deve ser empregada na internalização das externalidades da atividade produtiva, por meio de estímulos e punições, visando tornar mais (ou menos) atraentes determinadas ações para indivíduos e organizações (Buissa et al., 2017).

Entre os instrumentos de intervenção estatal, a Constituição Federal (1988) permite a realização de gastos tributários (tax expenditures), conhecidos também como benefícios fiscais ou gastos públicos indiretos, para alcançar objetivos econômicos e sociais, envolvendo a função indutora da norma tributária mais benéfica em relação ao sistema tributário padrão (Buissa et al., 2017; Lester, 2017). Dito de outra forma, os benefícios e as renúncias fiscais são faces de uma mesma moeda, compondo a extrafiscalidade tributária (Correia, 2016).

Assim, muitos países em desenvolvimento têm se empenhado em simplificar seu sistema, ampliando a base tributária, reduzindo as alíquotas e empregando cada vez mais os gastos tributários 
(Caldeira et al., 2020). Todavia, para remediar as falhas de mercado e promover a justiça social, os governos precisam adotar políticas de gastos tributários ótimas (Kalambokidis, 2014). Por essa razão, pesquisas empíricas sobre a sustentabilidade da política fiscal e a eficácia dos benefícios fiscais para investimentos nacionais e estrangeiros, principalmente em países em desenvolvimento, tornam-se cada dia mais importantes (Feld, Köhler \& Wolfinger, 2020; Parys \& James, 2010).

A propósito, um estudo de Armbruster e Hintermann (2020) analisou, em países da Organização para a Cooperação e o Desenvolvimento Econômico (OCDE), a interação estratégica dos governos regional e federal, bem como as externalidades fiscais resultantes da competição tributária inter-regional (spillovers), concluindo pela importância de corrigir as externalidades fiscais por meio do sistema de transferência fiscal. Na Alemanha, por exemplo, as alíquotas e as bases de cálculos dos principais tributos são fixados pelo governo federal, enquanto a arrecadação é de competência das unidades federadas, caracterizando o federalismo fiscal como mais cooperativo e centralizado, menos competitivo e descentralizado (Feld et al., 2020). À vista disso, no Brasil, é necessária uma ampla reforma tributária, que abranja tributos estaduais, municipais e federais, para a implantação de um federalismo fiscal cooperativo, que promova o desenvolvimento regional uniforme e sustentável, proporcionando sobretudo aos municípios, arrecadação tributária suficiente para cumprir a contento suas atribuições constitucionais.

De fato, não obstante a função primordial dos tributos consista na obtenção de recursos financeiros para que o Estado exerça suas funções constitucionais, eles também podem ser empregados para intervir em aspectos econômicos, sociais e ambientais, estimulando ou desestimulando determinadas atividades, como o consumo de bens e serviços e o desenvolvimento de localidades e regiões (Cavalcante, 2017). Logo, o Estado brasileiro, para implementar políticas públicas, incorporou a ideia do gasto tributário. Com isso, porém, renuncia a uma parcela de sua arrecadação tributária (Buissa et al., 2017). A renúncia fiscal, na verdade, pode ser efetiva ou potencial, considerando que, em geral, os métodos de cálculos utilizados por pesquisadores e governos não consideram as externalidades positivas dos benefícios fiscais, como a movimentação da economia, a atração de investimentos, as melhorias na infraestrutura pública, a geração de empregos e de renda.

Embora não haja uma definição única sobre gasto tributário, pode-se considerá-lo um gasto público indireto, realizado por meio da concessão de benefícios fiscais a contribuintes específicos, correspondendo a um desvio da estrutura básica do tributo (Buissa et al., 2017; Cavalcante, 2017; Pellegrini, 2014). Esse é o caso típico dos benefícios fiscais de ICMS, pois esse imposto foi concebido para ser essencialmente arrecadatório. Segundo a Receita Federal do Brasil (RFB, 2018), os gastos tributários devem: 1) compensar gastos realizados pelos contribuintes com serviços não atendidos pelo Estado; 2) compensar ações complementares às funções típicas de Estado, desenvolvidas por entidades civis; 3 ) promover a equalização de renda entre regiões; 4) incentivar determinado setor da economia.

A forma como são empregados os gastos tributários, todavia, é matéria contraditória, com diversos prós e contras. De acordo com Surrey (1970), mesmo que os problemas derivados dos gastos tributários sejam superados - por exemplo, renúncias fiscais, desequilíbrios competitivos, lucros inesperados (windfall profits) -, existem outras desvantagens no seu emprego, como as dificuldades no controle orçamentário e no estabelecimento de prioridades públicas, além do comprometimento da própria estrutura do tributo. Assim, Surrey (1970) recomenda, primeiro, a análise de alternativas relacionadas aos gastos públicos diretos e, posteriormente, caso se constate que a opção mais viável 
seja os gastos tributários, a verificação das vantagens obtidas e dos mecanismos de compensação da renúncia fiscal. No entanto, os gestores públicos, ao depararem com o trade-off entre equidade e eficiência, acabam não seguindo as prescrições das teorias de tributação ótima (Kalambokidis, 2014). Na prática, o fato de os gestores públicos estarem sujeitos aos ditames da política tributária, às influências de parlamentares e às pressões dos denominados "caçadores de renda" (rent-seekers) pode comprometer a tomada de decisão e a adoção da política tributária mais adequada à promoção do bem comum. Prova disso é a grande assimetria entre os beneficiários dos gastos tributários federais, que agrava a desigualdade regional - 29,6\% do total desses gastos tributários se destinam aos municípios mais ricos do Brasil, com maior PIB per capita, enquanto 2,4\% vão para os municípios mais pobres (Ministério da Economia, 2019).

De acordo com Kasdin (2018), um ponto positivo é que os gastos tributários operam sem uma estrutura burocrática de alocação de recursos e, se comparados aos programas baseados em gastos obrigatórios e discricionários, apresentam maior durabilidade, a qual é um fator importante no âmbito do orçamento público, como um indicador de trade-off entre resolução e capacidade de resposta às mudanças nos setores econômicos. Contudo, segundo destaca Lester (2017), na avaliação de programas de gastos tributários, deve-se, numa estrutura de custo-benefício, distinguir as medidas que têm objetivos econômicos das que têm objetivos sociais.

Por se tratar de diretrizes gerais relacionadas aos gastos tributários, porém, podem existir contextos aos quais elas não se aplicam (Surrey, 1970), como na persistente crise financeira em estados e municípios brasileiros. Nesse contexto, os gastos tributários representam uma alternativa viável na implementação de políticas públicas, desde que se acompanhem adequadamente as desonerações tributárias, a fim de evitar privilégios a setores econômicos e regiões nacionais (Botelho et al., 2019; Buissa et al., 2017; Rezende et al., 2019).

Nas leis orçamentárias brasileiras, entretanto, os demonstrativos regionalizados do efeito sobre as receitas e as despesas na concessão ou na ampliação de benefícios fiscais, quando existentes, não trazem explicações detalhadas sobre o método de cálculo e de compensação de renúncias fiscais (Pellegrini, 2014). Esse, no entanto, não se trata de um problema apenas brasileiro, uma vez que os gastos tributários nos Estados Unidos, por exemplo, raramente são discriminados nos orçamentos públicos e, em geral, não necessitam de reautorização, recebendo, por consequência, menos avaliações e escrutínios do que os gastos públicos diretos (Kalambokidis, 2014).

Ademais, diante das múltiplas variáveis a serem consideradas, há dificuldades na avaliação dos resultados dos benefícios fiscais, além do simples cálculo do montante de renúncia fiscal, acarretando incertezas sobre o grau de satisfatoriedade dessa política tributária e a perpetuação do gasto tributário (Buissa et al., 2017). Segundo Pellegrini (2014), existem basicamente dois métodos para calcular a renúncia fiscal: o de perda inicial, mais simples, que leva em conta apenas o montante que se deixou de arrecadar, considerando tudo o mais constante; e o de perda final, mais complexo, que considera os efeitos em cadeia, advindos da introdução de determinado gasto tributário, como as mudanças comportamentais dos contribuintes.

Além disso, ao incentivar o setor privado via concessão de benefícios fiscais, o Poder Público pode neutralizar os riscos inerentes aos negócios, desestimulando a economia, fato denominado por Sunstein (2014) como paradoxo da regulação, sobretudo quando a mensuração do custo-benefício da política pública abrange ampla escala e não se consegue identificar com clareza o que deve ser realizado. Vale destacar, porém, que os benefícios fiscais, em comparação com os subsídios governamentais, 
representam a melhor opção, considerando que obrigam as empresas a realizarem projetos somente quando há perspectiva de retorno econômico, já que elas devem respeitar os compromissos acordados com o poder público concedente (Porter, 1989). Trata-se, na verdade, de contrapartidas em favor de certas atividades de interesse público, do desenvolvimento de municípios com baixo IDH ou de regiões estratégicas, ou, ainda, da realização de aportes financeiros em favor de fundos públicos de cunho econômico, social ou ambiental. De qualquer maneira, conforme ressalta Cavalcante (2017, p. 200), os benefícios fiscais devem ser "concedidos com cautela e após rigorosa análise dos impactos orçamentários, uma vez que, sem controle ou em excesso, ensejam desequilíbrios na economia, ocasionando mais danos do que benefícios".

\subsection{Conceito triple bottom line na esfera do Poder Público}

Os desafios contemporâneos têm revelado a importância de encontrar a medida certa de intervenção estatal para fomentar o desenvolvimento sustentável, por meio da adoção do pensamento estratégico e da avaliação dos impactos globais, como o enfrentamento das externalidades da atividade produtiva e a dificuldade de preservação dos bens comuns [commons] (Freitas, 2016). Assim, ao interagir com os sistemas complexos da economia, da sociedade e do ambiente natural, com o estabelecimento de políticas públicas que fortaleçam a comunidade local, o desenvolvimento sustentável impõe os objetivos a serem perseguidos e alcançados por todas as nações (Freitas, 2016; J. Sachs, 2017).

O Poder Público, portanto, deve questionar os padrões de desenvolvimento econômico e adotar políticas direcionadas ao desenvolvimento sustentável, que ultrapassou o patamar de desejável para se tornar um requisito (Moura, 2015; Silva, Rebouças, Abreu \& Ribeiro, 2018). Mas, de acordo com Zhou, Liu e Cao (2014), nos países em desenvolvimento, como o Brasil, até que se alcance determinado nível de renda, o crescimento econômico ocorre de forma indiferente à conservação do meio ambiente. Não obstante, estudo realizado por Soares e Almeida (2018), investigando o desacoplamento do impacto ambiental do crescimento econômico sob cinco dimensões - atmosfera, terra, água, biodiversidade e saneamento -, concluiu que o crescimento econômico brasileiro tem sido acompanhado por melhorias quanto aos problemas ambientais, exceto na dimensão terra.

A sustentabilidade é um conceito interdisciplinar em constante evolução, contingencial a contextos culturais, temporais e locais, abrangendo dimensões sistêmicas e múltiplos critérios ligados à economia, à sociedade e ao meio ambiente (Nobre \& Ribeiro, 2013). Por conseguinte, o conceito triple bottom line (TBL), criado por Elkington (1998), na década de 1990, incorpora as três principais dimensões da sustentabilidade: prosperidade econômica, justiça social e qualidade ambiental. Na concepção original do TBL, Elkington (1998) considerou os construtos lucro, pessoas e planeta, representados por linhas simultâneas e integradas: a econômica (impacto das práticas de negócios no sistema econômico), a social (condução de práticas de negócios benéficas e justas em relação ao trabalho e à comunidade) e a ambiental (abrangendo a adoção de práticas de negócios que não comprometam os recursos ambientais para as gerações futuras).

A partir de então, ao tornar a sustentabilidade uma parte da agenda de negócios, o TBL reformulou o discurso da gestão, proporcionando o adequado balanceamento e importância às suas três dimensões (Alhaddi, 2015; Isil \& Hernke, 2017). Em suma, a dimensão da prosperidade econômica abrange as ações públicas e privadas, as quais devem estar centradas no adequado trade-off entre a eficiência e a equidade para a gestão eficiente dos recursos econômicos, o equilíbrio entre a produção de 
bens e serviços, além da justa distribuição da riqueza (Freitas, 2016; I. Sachs, 2008). A dimensão da justiça social, por sua vez, abrange os direitos sociais fundamentais, como nível adequado de homogeneidade social, pleno emprego, qualidade de vida e igualdade de acesso aos serviços sociais (I. Sachs, 2008). A dimensão da qualidade ambiental, por fim, abrange o duplo imperativo ético: a solidariedade sincrônica com a geração atual e a solidariedade diacrônica com as gerações futuras (I. Sachs, 2008). Esse duplo imperativo pode ser atingido com o auxílio da tributação com finalidade ambiental, a qual, por meio de maior gravame tributário, desestimula as condutas prejudiciais ao meio ambiente e, mediante concessão de benefícios fiscais, incentiva as condutas que promovem a proteção ou a conservação do meio ambiente (Cavalcante, 2012).

Apesar de o conceito TBL ter sido criado para a gestão de negócios, atualmente considerando a profunda mudança de paradigma que está ocorrendo em direção a uma mentalidade baseada na unidade planetária, ele é utilizado também na esfera pública (Elkington, 2020). Além disso, no Brasil, as dimensões do TBL estão vinculadas ao princípio constitucional da responsabilidade do Poder Público para a concretização solidária do desenvolvimento, socialmente inclusivo e ambientalmente limpo, de modo a assegurar o direito ao bem-estar presente e futuro (Freitas, 2016).

A Agenda 2030 (ONU, 2015) destaca a necessidade da participação efetiva dos governos municipais no desenvolvimento sustentável, ressaltando também a premência de uma reestruturação da tributação nos países em desenvolvimento, com a adoção de políticas fiscais que garantam maior equidade social e preservação ambiental. Ademais, Gomes, Osborne e Guarnieri (2020) observam que, como organização pública, os governos municipais devem ter como principal objetivo a prestação de serviços à população local.

A política tributária, portanto, exerce um papel importante na catalisação do crescimento econômico inclusivo, na região da América Latina e do Caribe, a partir da natureza multidimensional do desenvolvimento sustentável (OCDE, ONU, Centro Interamericano de Administrações Tributárias [CIAT], \& Banco Interamericano de Desenvolvimento [BID], 2020). Contudo, no debate sobre a sustentabilidade, tem-se priorizado as investigações sobre os efeitos dos gastos públicos diretos, negligenciando aqueles relacionados aos gastos tributários, que são instrumentos extrafiscais fundamentais na promoção do desenvolvimento sustentável (Redonda, 2016).

Considera-se ainda haver uma ligação entre a tributação, a inovação e o desenvolvimento sustentável, visto que, quanto mais um governo procura garantir o nascimento, o crescimento, a sobrevivência e a competitividade de empresas inovadoras e sustentáveis, mais deverá investir em normas tributárias que as apoiem (Accordino, 2020). Por essa razão, vários países têm reduzido a carga tributária dos impostos sobre valor agregado (IVA), a exemplo do ICMS, visando a objetivos não distributivos, como o apoio à mão de obra intensiva nas indústrias, a redução da carga tributária imposta a famílias de baixa renda e a internalização de externalidades ambientais (OCDE, 2020). Ademais, os benefícios fiscais de IVA encorajam, de muitas formas, as empresas a investirem na dimensão social e na economia circular, além de favorecer o abastecimento local na cadeia de suprimentos (Killian \& O’Regan, 2018).

Destacam-se também, no cenário do desenvolvimento sustentável, os green taxes ou ecotaxation, que são tributos ecologicamente orientados (Trennepohl, 2011). Contudo, ao contrário do que ocorre em certos países europeus, no Brasil não se pode tributar a emissão de gases poluentes, por exemplo, pois os tributos não podem ser uma sanção de ato ilícito, conforme previsto no Código Tributário Nacional (CTN) (Cavalcante, 2012). Apesar dessa limitação legal, tem sido comum o emprego da 
extrafiscalidade no ICMS direcionada à preservação (ou conservação) do meio ambiente, como é o caso do ICMS Ecológico, criado no Paraná, em 1991, o qual constitui não um novo imposto, e sim um mecanismo de repartição constitucional da arrecadação do ICMS entre os municípios, que considera nessa repartição, além dos critérios econômico e social, o ambiental (Moura, 2015; Trennepohl, 2011).

Não obstante a importância da extrafiscalidade para o desenvolvimento sustentável, as desonerações tributárias, aplicadas aos impostos de valor agregado, são muitas vezes mal-orientadas, pois acabam oferecendo maiores benefícios, em termos absolutos, às famílias mais ricas (OCDE, 2020). Ou seja, trata-se do costumeiro problema da regressividade dos impostos indiretos. Assim, diante de um cenário econômico instável e de elevada desigualdade como o brasileiro, é preciso que o Estado adote um modelo econômico sustentável, devendo, para tanto, optar pela tributação progressiva e pelo aprimoramento do controle na concessão de benefícios fiscais (Mélo \& Oliveira, 2019). Além disso, é necessário verificar quanto a substituição dos investimentos públicos pelos subsídios e pelas desonerações tributárias pode ter afetado o desempenho da economia brasileira, permitindo que o debate sobre política fiscal transcenda a esfera da especulação ideológica e se concentre na análise embasada em evidências empíricas sólidas (Gobetti \& Orair, 2017).

\subsection{Guerra fiscal e benefícios de ICMS em Santa Catarina}

Cabe esclarecer, para início de conversa, que o ICMS descende do ICM - imposto sobre operações relativas à circulação de mercadorias -, previsto na Constituição Federal de 1967, o qual, por sua vez, tem raízes no IVC - imposto sobre vendas e consignações - da Constituição Federal de 1946 (Carrazza, 2015). Todos esses tributos, porém, descendem do imposto sobre valor agregado (IVA), baseado no princípio da não cumulatividade. Segundo Balthazar (2008), o IVA, embora seja assim entendido, não foi concebido originalmente na França; é, de fato, fruto de um processo normativo evolutivo, cujo início pode ser atribuído à criação, na Bélgica, da "taxa sobre pagamentos", por meio da Lei de 31 de dezembro de 1917.

Soares, Gomes e Toledo (2011, p. 460) destacam a importância do ICMS "na política fiscal e nos orçamentos públicos, especialmente naqueles municípios de menor porte, em que sua existência depende, em boa parte, dessa fonte de recurso". Nessa linha, no Brasil, desde a década de 1980, diante da ausência de efetiva política nacional de desenvolvimento regional, os estados passaram a conceder benefícios fiscais de ICMS, de modo a atrair empreendimentos aos seus territórios, visando, com isso, incrementar a movimentação econômica e gerar mais empregos, numa competição conhecida como guerra fiscal (Afonso, 2014; Buissa et al., 2017).

A guerra fiscal, contudo, tem levado à instauração do federalismo competitivo, ao invés do federalismo cooperativo, além de provocar insegurança jurídica nos contribuintes que usufruem das desonerações tributárias, diante das retaliações dos fiscos dos estados que se sentem prejudicados. Conforme Rezende (2020, p. 73), "a manutenção da competência tributária estadual de um imposto notoriamente de caráter nacional é combustão para uma guerra claramente oposta à cooperação sinalizada pela Constituição Federal de 1988”. Assim, segundo Oliveira e Chieza (2018), é preciso eliminar os mecanismos da guerra fiscal e transformar os principais tributos estaduais e municipais num IVA, com campo de incidência amplo e estruturado no princípio da cobrança no destino, e ao mesmo tempo reduzir a regressividade do Sistema Tributário Nacional com o aumento da participação dos impostos sobre a renda e o patrimônio. 
É nesse sentido que Appy, Santi, Coelho, Machado e Canado (2020) propõem uma reforma tributária que inclua a substituição progressiva dos atuais cinco tributos brasileiros incidentes sobre bens e serviços (ICMS, ISS [imposto sobre serviços de qualquer natureza], IPI [imposto sobre produtos industrializados], PIS [Programa de Integração Social] e Cofins [Contribuição para o Financiamento da Seguridade Social]) pelo denominado Imposto sobre Bens e Serviços (IBS), previsto na Proposta de Emenda à Constituição no 45 (PEC 45) (Proposta de Emenda à Constituição no 45, de 3 de abril de 2019), que incide sobre a operação de aquisição para o consumo e veda a concessão de benefícios fiscais, cuja arrecadação e fiscalização são partilhadas entre a União, os estados e os municípios.

Ante esse panorama federativo conflituoso, foi promulgada a Lei Complementar $n^{\circ} 160$ (Lei Complementar $n^{\circ} 160$, de 7 de agosto de 2017), que permitiu a convalidação dos benefícios fiscais de ICMS concedidos sem a prévia celebração de convênio autorizativo no Conselho Nacional de Política Fazendária (Confaz). Não obstante, essa norma complementar conferiu legalidade a benefícios fiscais que antes eram considerados inconstitucionais, fato que revela a dificuldade em convergir os interesses da federação com os interesses individuais dos estados (Rezende, 2020).

Em Santa Catarina, lócus deste estudo, a concessão do benefício fiscal de crédito presumido é responsável pelo maior montante de gastos tributários (renúncia fiscal), se comparado ao da concessão dos benefícios fiscais de redução de base de cálculo e de isenção. Exemplificando, no estado catarinense, em 2019, o montante de renúncia fiscal de ICMS totalizou 5,7 bilhões de reais, assim divididos: crédito presumido, 4,1 bilhões; redução de base de cálculo, 920 milhões; e isenção, 689 milhões (Lei $\mathrm{n}^{\circ}$ 17.566, de 7 de agosto de 2019).

Conforme consta na Lei de Diretrizes Orçamentárias (Lei no 17.566, de 7 de agosto de 2019), todavia, o valor da renúncia fiscal de ICMS é potencial, o que significa que Santa Catarina não deixou de arrecadar efetivamente 5,7 bilhões de reais, pois, no cálculo da renúncia fiscal, não se consideram outras variáveis, como o fato de determinadas empresas terem se instalado, permanecido ou ampliado seus negócios no estado graças exclusivamente à concessão de benefícios fiscais. Ou seja, Santa Catarina emprega o método de perda inicial para estimar a renúncia fiscal, e não o método de perda final, que considera os efeitos em cadeia dos benefícios fiscais de ICMS (Pellegrini, 2014).

Apesar das externalidades negativas, em especial na esfera da guerra fiscal, vários estudos apontam efeitos positivos na política de concessão de benefícios fiscais, conforme exposto na sequência.

Em âmbito internacional, Accordino (2020) analisou os benefícios fiscais concedidos na Itália, concluindo que eles promovem o aumento da demanda por bens e serviços, bem como a criação e o crescimento de empresas inovadoras, comprometidas com a promoção do desenvolvimento sustentável. Chicumbi (2018) avaliou os impactos das desonerações num imposto industrial de Angola, concluindo que elas resultaram na atração de investimentos, na geração de empregos, no incremento do PIB e na redução das assimetrias regionais. Da mesma forma, Parys e James (2010) avaliaram os benefícios fiscais concedidos em países da África Subsaariana, concluindo que o aumento da segurança jurídica, a redução da complexidade do sistema tributário e, em menor grau, a redução da tributação auxiliam na atração de investimentos. He et al. (2019) investigaram as relações entre os impostos ambientais e os desempenhos econômico e ambiental na China, concluindo que se deve reduzir a tributação para encorajar o surgimento de indústrias sustentáveis, com baixa emissão de teor de carbono e alta tecnologia. De forma semelhante, Qi et al. (2020) verificaram que os benefícios fiscais do IVA na China impulsionam a capacidade de inovação corporativa regional, além do desenvolvimento científico e tecnológico. Já Kleinbard (2010), contrariando o entendimento de Surrey (1970), concluiu 
que, nos Estados Unidos, os gastos tributários podem ser os meios mais eficientes para conceder subsídios governamentais, a ponto de se tornarem instrumentos dominantes na implementação de políticas públicas discricionárias. Por fim, Klemm e Parys (2012), no âmbito da América Latina e do Caribe, encontraram evidências robustas de que a concessão de benefícios fiscais de longo prazo são instrumentos efetivos para atrair investimentos internacionais.

Em âmbito nacional, Botelho et al. (2019) avaliaram as políticas de benefícios fiscais nas relações com o desenvolvimento regional, concluindo que as desonerações com foco em regiões específicas obtiveram melhores resultados, quando comparadas àquelas de abrangência nacional. Do mesmo modo, Porto e Memória (2019), ao investigarem os efeitos dos incentivos fiscais federais, previstos na Lei $n^{\circ} 11.196$, de 2005, concluíram que houve incremento nos investimentos em pesquisa e desenvolvimento, além da geração de valor para a sociedade. Rezende et al. (2018), ao analisarem a relação entre os benefícios fiscais federais, estaduais e municipais, bem como as decisões corporativas relativas a investimentos e resultados, concluíram que as desonerações tiveram impacto positivo na geração de valor para as empresas beneficiadas.

Em âmbito estadual, Rezende et al. (2019), tendo por base o município sul-mato-grossense de Três Lagoas, investigaram se os benefícios fiscais de ICMS contribuem para a criação de valor, concluindo que houve incremento na arrecadação e aumento substancial no repasse da cota-parte constitucional de ICMS, além da atração de número expressivo de empresas para a localidade e retorno econômico considerável para as empresas beneficiárias. Por último, Sá e Silva (2019) analisaram o projeto de desconcentração industrial, desenvolvido na região metropolitana de Curitiba, ancorado na concessão de benefícios fiscais de ICMS, concluindo que o projeto foi eficiente na formação do espaço industrial local, apesar de não apresentar o mesmo resultado nas demais regiões do estado.

\subsection{Hipóteses de pesquisa e modelo teórico}

Ante as conclusões dos estudos de Accordino (2020), Chicumbi (2018), He et al. (2019), Klemm e Parys (2012), Parys e James (2010), Porto e Memória (2019), Qi et al. (2020), Rezende, Dalmácio e Rathke (2018), Rezende, Peralta, Rosa e Rezende (2019), assim como Sá e Silva (2019), descritas no subitem 2.3, que apontam resultados positivos na relação entre gastos tributários, atração de empreendimentos e sustentabilidade no conceito TBL, formulam-se na sequência as hipóteses de pesquisa, as quais se inter-relacionam:

Hipótese $\mathrm{H}_{1}$ : "Os gastos tributários de ICMS se relacionam, positivamente, com a prosperidade econômica dos municípios catarinenses".

Hipótese $\mathrm{H}_{2}$ : "Os gastos tributários de ICMS se relacionam, positivamente, com a justiça social dos municípios catarinenses".

Hipótese $\mathrm{H}_{3}$ : "Os gastos tributários de ICMS se relacionam, positivamente, com a qualidade ambiental dos municípios catarinenses".

Na Figura 1, apresenta-se o modelo teórico de pesquisa e indicam-se graficamente as referidas hipóteses de pesquisa. 


\section{FIGURA 1 MODELO TEÓRICO}

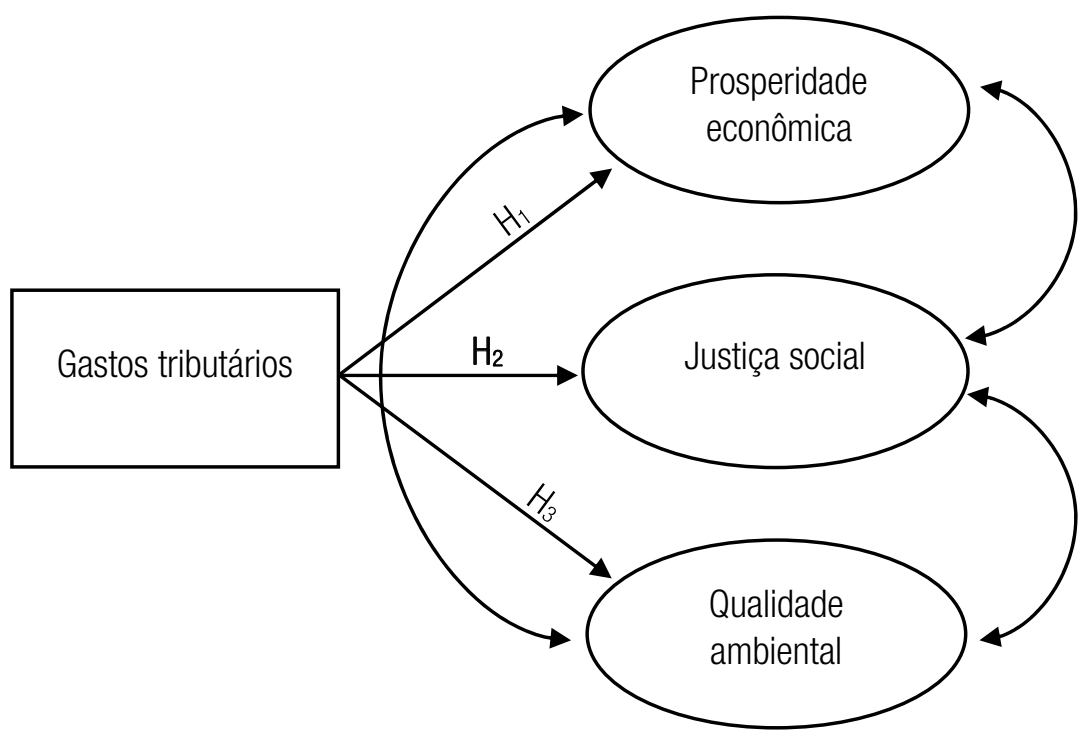

Fonte: Elaborada pelos autores.

Considerando que o objetivo deste artigo é analisar a influência dos benefícios fiscais de ICMS na sustentabilidade dos municípios catarinenses, o modelo teórico (Figura 1), concebido com base na fundamentação teórica desta pesquisa, apresenta a variável (observável) "gastos tributários" (Buissa et al., 2017; Caldeira et al., 2020; Lester, 2017; RFB, 2018; Surrey, 1970), composta dos montantes totais (estimados) de renúncia fiscal de ICMS, descritos nas Leis de Diretrizes Orçamentárias (LDO) do estado de Santa Catarina. No que tange à sustentabilidade dos municípios, o modelo teórico apresenta os construtos "prosperidade econômica", "justiça social" e "qualidade ambiental", ancorados no conceito TBL (Alhaddi, 2015; Elkington, 1998; Isil \& Hernke, 2017). Assim, o modelo concebido, se bem que baseado nas teorias relacionadas à extrafiscalidade tributária e à sustentabilidade no TBL, é inovador e experimental, haja vista que apresenta um conjunto de relações múltiplas e integradas, ligadas a uma relevante questão, tanto empírica quanto teórica, conforme exposto ao longo da fundamentação teórica: gastos tributários versus sustentabilidade econômica, social e ambiental.

\section{MÉTODO}

Esta pesquisa se classifica como teórico-empírica, com desenho longitudinal e período especificado de antemão, empregando o método quantitativo, mediante a formulação de hipóteses (Sampieri, Collado \& Lucio, 2013). A revisão da literatura foi realizada por consulta a capítulos de livros, artigos acadêmicos, estudos técnicos e legislações. O universo da pesquisa é composto dos atuais 295 municípios do estado de Santa Catarina, e os dados utilizados foram coletados no período de 2005 a 2017. O ano de 2005 foi escolhido como início pelo fato de os dados de arrecadação de ICMS estarem disponíveis somente a partir dessa data, e 2017 foi escolhido como o ano final em razão de parte dos dados do Instituto Brasileiro de Geografia e Estatística (IBGE) serem disponibilizados com defasagem de um a dois anos. 
O recorte transitório da pesquisa constitui um aglomerado de séries temporais e de dados de corte transversal, resultando num conjunto de dados em painel, sendo que, para ser considerado balanceado, a quantidade $\mathrm{T}$ de períodos deve ser $\mathrm{T} 1=\mathrm{T} 2=\mathrm{T} 3=\mathrm{T}$, e a quantidade de observações no banco de dados (N) deve ser igual a n.T (Fávero \& Belfiore, 2017). Nesta pesquisa, contudo, o painel de dados é considerado desbalanceado, uma vez que o período de 13 anos não é igual para todas as unidades de observação. Ademais, os dados da pesquisa foram tabulados na estrutura de dados em painel id $j v$, na qual id representa a unidade de análise e $j v$ representa o período, constituindo-se num painel curto, considerando que o número de observações $(\mathrm{M})$ no corte transversal é maior que o de períodos de tempo (T), isto é, $M>$ T [295 > 13] (Fávero \& Belfiore, 2017). Feld et al. (2020), Klemm e Parys (2012), Parys e James (2010), bem como Qi et al. (2020), de modo semelhante, também empregaram modelos de séries temporais, com dados em painel, para analisar a influência da política tributária sobre o desenvolvimento econômico e a sustentabilidade multidimensional.

As variáveis referentes ao triple bottom line (Tabela 1), obtidas de fontes secundárias, parte delas de natureza dicotômica, foram definidas com base na fundamentação teórica, em especial: 1) nos estudos de Silva et al. (2018), o qual aborda a construção de um índice de desenvolvimento sustentável nos municípios cearenses, e de Malheiros, Coutinho e Philippi (2012), que apresenta uma abordagem conceitual dos indicadores de sustentabilidade; 2) na obra referência de J. Sachs (2017), A era do desenvolvimento sustentável; e 3) nos indicadores de desenvolvimento sustentável do IBGE (2015).

A seguir, na Tabela 1 se descrevem as variáveis que compõem os construtos "prosperidade econômica", "justiça social" e "qualidade ambiental", os quais representam as dimensões da sustentabilidade municipal.

\section{TABELA 1 VARIÁVEIS QUE COMPÕEM OS CONSTRUTOS DA PESQUISA}

\begin{tabular}{|c|c|c|}
\hline Construtos & Descrição das variáveis & Fonte \\
\hline \multirow{7}{*}{ 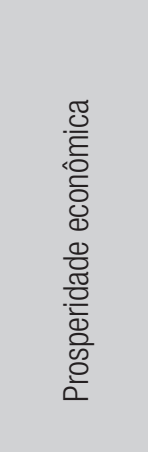 } & $Y_{1}-$ Valor adicionado bruto (em reais, log natural) & IBGE \\
\hline & $\mathrm{Y}_{2}-$ Consumo de energia (em kWh, log natural) & Celesc \\
\hline & $\mathrm{Y}_{3}-$ Frota de veículos (número, log natural) & Denatran \\
\hline & $\mathrm{Y}_{4}-$ População (número, log natural) & STN \\
\hline & $Y_{5}-$ Despesas correntes (em reais, log natural) & STN \\
\hline & $\mathrm{Y}_{6}-$ Receitas correntes (em reais, log natural) & STN \\
\hline & $\mathrm{Y}_{7}$ - Cota-parte do Fundo de Participação dos Municípios (em reais, log natural) & STN \\
\hline \multirow{7}{*}{ 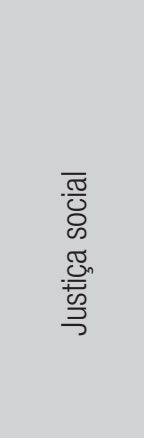 } & $\mathrm{Y}_{8}-$ Arrecadação com o ICMS (em reais, log natural) & SEF \\
\hline & $Y_{9}$ - Número de óbitos & IBGE \\
\hline & $\mathrm{Y}_{10}-$ Índice Firjan de Desenvolvimento Municipal de Saúde & Firjan \\
\hline & $Y_{11}$ - Índice Firjan de Desenvolvimento Municipal de Educação & Firjan \\
\hline & $\mathrm{Y}_{12}$ - Índice Firjan de Desenvolvimento Municipal de Emprego e Renda & Firjan \\
\hline & $Y_{13}-$ Cooperativas ou associações de catadores (dicotômico - $[0,1]$ ) & SNIS \\
\hline & $\mathrm{Y}_{14}-$ Trabalho social das prefeituras para catadores (dicotômico $-[0,1]$ ) & SNIS \\
\hline
\end{tabular}




\begin{tabular}{|c|c|c|}
\hline Construtos & Descrição das variáveis & Fonte \\
\hline \multirow{6}{*}{ 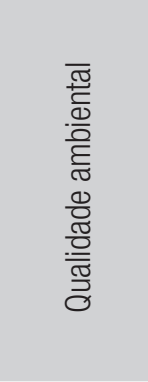 } & $\mathrm{Y}_{15}$ - Limpeza pública e manejo de resíduos sólidos (dicotômico - $[0,1]$ ) & SNIS \\
\hline & $Y_{16}-$ Drenagem urbana e manejo de águas pluviais (dicotômico - $[0,1]$ ) & SNIS \\
\hline & $Y_{17}-$ Garantia de saúde pública (dicotômico - $[0,1]$ ) & SNIS \\
\hline & $\mathrm{Y}_{18}-$ Abastecimento de água (dicotômico $\left.-[0,1]\right)$ & SNIS \\
\hline & $Y_{19}-$ Esgotamento sanitário (dicotômico - $[0,1]$ ) & SNIS \\
\hline & $Y_{20}-$ Mecanismos de participação e controle social (dicotômico - $[0,1]$ ) & SNIS \\
\hline
\end{tabular}

Notas: Siglas/acrônimos: IBGE (Instituto Brasileiro de Geografia e Estatística); Celesc (Centrais Elétricas de Santa Catarina); Denatran (Departamento Nacional de Trânsito); STN (Secretaria do Tesouro Nacional); SEF (Secretaria de Estado da Fazenda de Santa Catarina); Firjan (Federação das Indústrias do Estado do Rio de Janeiro); SNIS (Sistema Nacional de Informações sobre Saneamento).

Fonte: Elaborada pelos autores.

Em relação às variáveis que compõem o construto "prosperidade econômica, utiliza-se um conjunto de variáveis relevantes para a sustentabilidade econômica municipal, como receita tributária, valor adicionado, população, consumo de energia elétrica, frota de veículos, despesas e receitas correntes (IBGE, 2015; Malheiros et al., 2012; Silva et al., 2018), não se limitando ao mero PIB per capita, pois, segundo J. Sachs (2017, p. 28), “o aumento do PIB per capita está longe de ser um indicador perfeito do bem-estar".

Quanto às variáveis do construto "justiça social”, elas refletem as políticas públicas que, em conjunto, geram a inclusão e o desenvolvimento social homogêneos nos municípios. Assim, os estudos de Malheiros et al. (2012), J. Sachs (2017) e Silva et al. (2018) salientam a relevância dos indicadores selecionados. Deve-se destacar que as variáveis "cooperativas ou associações de catadores" e "trabalho social das prefeituras para catadores" constituem indicadores importantes, considerando que a Lei no 12.305 (Lei no 12.305, de 2 de agosto de 2010), que institui a Política Nacional de Resíduos Sólidos (PNRS), delega aos municípios a gestão integrada dos resíduos sólidos gerados nos respectivos territórios (art. 10), priorizando o acesso aos recursos federais àqueles municípios que implantarem a coleta seletiva com a participação de cooperativas ou outras formas de associação de catadores de materiais reutilizáveis e recicláveis (art. 18, II). Além disso, a PNRS, ao estabelecer metas arrojadas para o equacionamento dos problemas ambientais e sociais relacionados aos resíduos urbanos, prevê a inclusão dos catadores na cadeia reversa dos materiais recicláveis em todos os municípios (Teodósio, Dias \& Santos, 2016).

Por fim, no que tange às variáveis que compõem o construto "qualidade ambiental", elas abrangem um conjunto de ações alinhadas às boas práticas de preservação e conservação do meio ambiente, sobretudo diante do fato de a Constituição Federal de 1988 delegar aos municípios a prestação dos serviços públicos locais essenciais (art. 30,V), como é o caso da limpeza pública, do manejo de resíduos sólidos, do abastecimento de água e do esgotamento sanitário (IBGE, 2015; Malheiros et al., 2012; J. Sachs, 2017; Silva et al., 2018). Observa-se ainda que a variável "mecanismos de participação e controle social" se refere ao estabelecimento de mecanismos e controles de cunho social, precondição para a implementação da política pública de saneamento básico (Decreto n 7.2017, de 21 de julho de 2010).

No que concerne à variável (observável) "gastos tributários", trata-se de uma proxy composta do somatório dos montantes anuais (estimados) de renúncia fiscal (potencial) de ICMS, derivados da concessão de crédito presumido, de redução de base de cálculo e de isenção, publicados nas LDOs 
catarinenses entre 2006 e 2016. Na apropriação dos montantes de renúncia fiscal, para cada um dos 295 municípios catarinenses, foram aplicados os índices anuais de valor adicionado - utilizados pelo Estado no repasse constitucional da arrecadação de ICMS aos municípios -, publicados pela Secretaria de Estado da Fazenda de Santa Catarina, sobre 25\% do montante da renúncia fiscal obtido na LDO.

Os dados monetários desta pesquisa foram deflacionados pelo índice FGV IGP-DI (ano-base 2017), e as variáveis contínuas foram tratadas com a utilização de logaritmo natural, visando reduzir a escala das variáveis e a heterogeneidade.

Para analisar as relações entre a variável "gastos tributários" e os construtos "prosperidade econômica", "justiça social" e "qualidade ambiental", utilizou-se a técnica de modelagem de equações estruturais (MEE) generalizada, com base em covariâncias. A aplicação da MEE é recomendada para as pesquisas empíricas em administração, já que possibilita a mensuração de construtos latentes e o teste simultâneo de teorias com múltiplas relações de dependência, caracterizando-se como uma extensão da análise fatorial confirmatória (AFC) e uma regressão múltipla (Bido, Silva, Souza \& Godoy, 2010; Hair, Black, Babin, Anderson \& Tatham, 2009). Nesse mesmo alinhamento, Hall e Kanaan (2020) optaram pelo modelo de equações estruturais para estimar os efeitos das escolhas tributárias locais (trade-offs) sobre o desenvolvimento econômico de 215 municípios do estado do Texas, nos Estados Unidos, cujos dados, obtidos de fontes secundárias, abrangeram o período entre 2011 e 2015, o que proporcionou uma quantidade substancial de variáveis para a MEE e garantiu uma investigação significativa.

Considerando que as variáveis desta pesquisa foram predefinidas com base no referencial teórico, aplicou-se inicialmente a AFC, utilizando o estimador de máxima verossimilhança, em geral empregado nos modelos de estrutura pooled com clusterização (caso desta pesquisa), que possibilita o controle da heterogeneidade (Fávero, 2013). O número de variáveis observáveis nesta pesquisa está de acordo com as prescrições de Hair et al. (2009, p. 601): “[...] os construtos latentes devem ser indicados por, pelo menos, três variáveis medidas sendo preferível que sejam quatro ou mais".

Apesar das várias tentativas e adaptações efetuadas no modelo, no entanto, os resultados não foram satisfatórios, uma vez que a estrutura informacional desta pesquisa apresenta variáveis dicotômicas e valores omissos, gerando o problema da não concavidade (Bertolai, 2009). Para superar esse problema, os construtos "prosperidade econômica", "justiça social" e "qualidade ambiental" foram estimados de forma independente, o que possibilitou trabalhar os dados em formato de painel, considerando a heterogeneidade dos municípios, além de viabilizar a obtenção de resultados mais robustos no que tange ao desvio padrão dos erros.

Após a estimação do modelo por meio da AFC, verificou-se se as variáveis se comportavam de acordo com expectativas teóricas (Aranha \& Zambaldi, 2008; Hair et al., 2009), resultando no Modelo 1. Em seguida, procedeu-se ao refinamento do Modelo 1 pela exclusão das variáveis com cargas fatoriais padronizadas inferiores a 0,5 (Figueiredo \& Silva, 2010; Hair et al., 2009), resultando no Modelo 2.

$\mathrm{Na}$ sequência, compararam-se os efeitos dos ajustes que resultaram nos Modelos 1 e 2, selecionando-se o modelo mais adequado para esta pesquisa, com base nos resultados do ajuste geral (Hair et al., 2009). Além disso, verificou-se a consistência interna dos construtos por meio da aplicação dos testes de confiabilidade composta, de análise de variância extraída e de validade discriminante (Prado, 2006). 


\section{ANÁLISE E DISCUSSÃO DOS RESULTADOS}

Na Tabela 2, são apresentados os resultados da análise fatorial confirmatória (AFC), segundo os Modelos 1 (original) e 2 (refinado), no que tange às variáveis que compõem os construtos "prosperidade econômica", "justiça social" e "qualidade ambiental".

\section{TABELA 2 RESULTADOS DA ESTIMAÇÃO DAS VARIÁVEIS QUE COMPÕEM OS CONSTRUTOS DA PESQUISA}

\begin{tabular}{|c|c|c|c|}
\hline Construtos & Descrição das variáveis & Modelo 1 & Modelo 2 \\
\hline \multirow{8}{*}{ 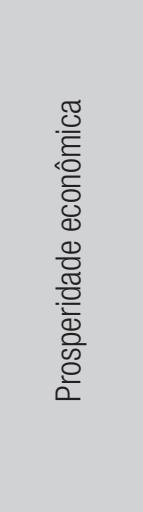 } & $Y_{1}-$ Valor adicionado bruto & 0,979 & 0,979 \\
\hline & $Y_{2}-$ Consumo de energia & 0,661 & 0,661 \\
\hline & $Y_{3}-$ Frota de veículos & 0,976 & 0,976 \\
\hline & $Y_{4}-$ População & 0,974 & 0,974 \\
\hline & $Y_{5}-$ Despesas correntes & 0,860 & 0,860 \\
\hline & $Y_{6}-$ Receitas correntes & 0,973 & 0,973 \\
\hline & $Y_{7}$ - Cota-parte do Fundo de Participação dos Municípios & 0,917 & 0,917 \\
\hline & $Y_{8}-$ Arrecadação com o ICMS & 0,905 & 0,905 \\
\hline \multirow{5}{*}{ 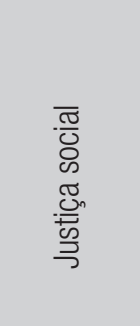 } & $Y_{9}-$ Número de óbitos & 0,852 & 0,870 \\
\hline & $Y_{10}$ - Índice Firjan de Desenvolvimento Municipal de Saúde & 0,182 & - \\
\hline & $Y_{11}$ - Índice Firjan de Desenvolvimento Municipal de Educação & 0,152 & - \\
\hline & $Y_{12}$ - Índice Firjan de Desenvolvimento Municipal de Emprego e Renda & 0,432 & 0,426 \\
\hline & $Y_{13}-$ Cooperativas ou associações de catadores & 0,601 & 0,588 \\
\hline \multirow{7}{*}{ 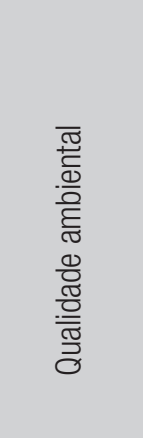 } & $Y_{14}-$ Trabalho social das prefeituras para catadores & 0,445 & 0,436 \\
\hline & $Y_{15}-$ Limpeza pública e manejo de resíduos sólidos & 0,740 & 0,740 \\
\hline & $Y_{16}-$ Drenagem urbana e manejo de águas pluviais & 0,701 & 0,701 \\
\hline & $Y_{17}-$ Garantia de saúde pública & 0,995 & 0,995 \\
\hline & $Y_{18}-$ Abastecimento de água & 0,994 & 0,994 \\
\hline & $Y_{19}-$ Esgotamento sanitário & 0,894 & 0,894 \\
\hline & $Y_{20}-$ Mecanismos de participação e controle social & 0,835 & 0,835 \\
\hline
\end{tabular}

Fonte: Elaborada pelos autores.

Observando-se a Tabela 2, vale destacar que todas as variáveis dos construtos "prosperidade econômica" e "qualidade ambiental" apresentam coeficientes superiores a 0,5, resultado que indica que essas variáveis representam, adequadamente, os construtos. Como não ocorreu a exclusão de variáveis nesses construtos, os quais foram estimados de forma independente, os resultados obtidos, tanto no Modelo 1 quanto no 2, são idênticos. Todavia, no construto "justiça social", as variáveis 
$\mathrm{Y}_{10}$ - Índice Firjan de Desenvolvimento Municipal de Saúde $(0,182)$ - e $\mathrm{Y}_{11}$ - Índice Firjan de Desenvolvimento Municipal de Educação $(0,152)$ - apresentam coeficientes muito inferiores a 0,5, o que resultou na exclusão dessas variáveis no Modelo 2 (Hair et al., 2009; Figueiredo \& Silva, 2010). Quanto à variável $Y_{12}$ - Índice Firjan de Desenvolvimento Municipal de Emprego e Renda $(0,432)$-, apesar do coeficiente um pouco abaixo de 0,5, optou-se por mantê-la no Modelo 2 em razão de sua importância teórica para compor o construto "justiça social” e da restrição dos graus de liberdade desse construto (Bomfim, Almeida, Gouveia, Macedo \& Marques, 2011; Figueiredo \& Silva, 2010).

Na Tabela 3, são apresentados os resultados da AFC na estimação de cada construto em relação à variável "gastos tributários", bem como a estimação das covariâncias entres os construtos.

\section{TABELA 3 RESULTADOS DAS ESTIMAÇÕES DOS CONSTRUTOS EM RELAÇÃO À VARIÁVEL “GASTOS TRIBUTÁRIOS" E DAS COVARIÂNCIAS ENTRE OS CONSTRUTOS}

\begin{tabular}{|c|c|c|c|}
\hline Variável & Construtos & Modelo 1 & Modelo 2 \\
\hline \multirow{3}{*}{ Gastos tributários } & Prosperidade econômica & 0,823 & 0,823 \\
\hline & Justiça social & 0,656 & 0,647 \\
\hline & Qualidade ambiental & 0,152 & 0,152 \\
\hline \multicolumn{4}{|l|}{ Covariâncias } \\
\hline \multicolumn{2}{|c|}{ Prosperidade econômica, Justiça social } & 0,5060 & 0,5050 \\
\hline \multicolumn{2}{|c|}{ Prosperidade econômica, Qualidade ambiental } & $-0,0698$ & $-0,0697$ \\
\hline \multicolumn{2}{|c|}{ Justiça social, Qualidade ambiental } & $-0,0272$ & $-0,0382$ \\
\hline
\end{tabular}

Fonte: Elaborada pelos autores.

Mesmo com a exclusão das variáveis $Y_{10}$ - Índice Firjan de Desenvolvimento Municipal de Saúde - e $\mathrm{Y}_{11}$ - Índice Firjan de Desenvolvimento Municipal de Educação -, existem poucas variações nos coeficientes estimados nos dois modelos (Tabela 3). Assim, para verificar a consistência interna dos construtos e, por consequência, investigar qual desses dois modelos deve ser utilizado no modelo de equações estruturais, aplicaram-se testes de confiabilidade composta (CC), de análise de variância extraída (AVE) e de análise discriminante (Tabelas 4 e 5). 
TABELA 4 RESULTADOS DOS TESTES DE CONFIABILIDADE COMPOSTA E DE ANÁLISE DE VARIÂNCIA EXTRAÍDA

\begin{tabular}{lccccc}
\hline Construtos & \multicolumn{2}{c}{ Modelo 1 } & \multicolumn{3}{c}{ Modelo 2} \\
\hline Prosperidade econômica & CC & AVE & CC & AVE \\
Justiça social & 0,975 & 0,830 & 0,975 & 0,830 \\
Qualidade ambiental & 0,613 & 0,255 & 0,681 & 0,369 \\
\hline
\end{tabular}

Fonte: Elaborada pelos autores.

Segundo Hair et al. (2009) e Kline (2016), os coeficientes para o teste de confiabilidade composta devem ser iguais ou superiores a 0,7. Esse parâmetro é suportado nos dois modelos (Tabela 4) no que se refere aos construtos "prosperidade econômica" e "qualidade ambiental". Porém, quanto ao construto "justiça social", o coeficiente é superior no Modelo 2, embora um pouco abaixo de 0,7. No que concerne ao teste de análise de variância extraída, os coeficientes devem ser iguais ou superiores a 0,5 (Hair et al., 2009; Kline, 2016). No construto “justiça social”, os coeficientes são inferiores a 0,5 nos dois modelos, porém no Modelo 2 o coeficiente é ligeiramente superior (Tabela 4).

Os resultados do teste de análise discriminante, que consiste na comparação do quadrado da correlação entre os construtos e a análise de variância extraída dos construtos para os dois modelos, são apresentados na Tabela 5.

TABELA 5 RESULTADOS DO TESTE DE ANÁLISE DISCRIMINANTE

\begin{tabular}{lccccccc} 
Construtos & \multicolumn{3}{c}{ Modelo 1} & \multicolumn{3}{c}{ Modelo 2} \\
\hline Prosperidade econômica (PE) & PE & JS & QA & PE & JS & QA \\
Justiça social (JS) & 0,830 & & & 0,830 & & \\
Qualidade ambiental (QA) & 0,573 & 0,255 & & 0,564 & 0,369 & 0,753
\end{tabular}

Fonte: Elaborada pelos autores.

Numa análise discriminante, espera-se que o resultado da análise de variância extraída (AVE) na diagonal seja maior que o do quadrado da correlação entre os construtos, indicando, assim, que as variáveis de determinado construto explicam mais sobre esse construto do que os outros construtos do modelo. No entanto, observa-se nos resultados (Tabela 5) que, tanto no Modelo 1 quanto no 2, o construto "prosperidade econômica" está mais relacionado ao construto "justiça social" do que o observado na análise de variância extraída desse construto (Tabela 4), sugerindo que as variáveis do construto "prosperidade econômica" são explicativas do construto "justiça social”. Todavia, esse resultado pode ser justificado pelo fato de as variáveis econômicas possibilitarem melhor acesso à saúde, à segurança e à educação (I. Sachs, 2008; J. Sachs, 2017). 
Assim, por obter resultados de ajustes superiores ao Modelo 1, optou-se pelo Modelo 2 para compor o modelo de equações estruturais. Em relação aos ajustes globais do Modelo 2, o coeficiente de determinação foi de 0,687 , indicando que esse modelo explica $69 \%$ da variabilidade dos dados, o que representa um ajuste satisfatório de predição do modelo (Marôco, 2014; Schumacker \& Lomax, 2016). Além disso, os resultados da análise de estabilidade de sistemas de equações simultâneas apontam que todos os autovalores estão dentro do círculo unitário, ou seja, que o Modelo 2 tem estabilidade condicional (Marôco, 2014; Schumacker \& Lomax, 2016).

Na Figura 2 são apresentados, na forma de diagrama, os resultados do modelo de equações estruturais.

\section{FIGURA 2 RESULTADOS DA ESTIMAÇÃO DO MODELO DE EQUAÇÕES ESTRUTURAIS}

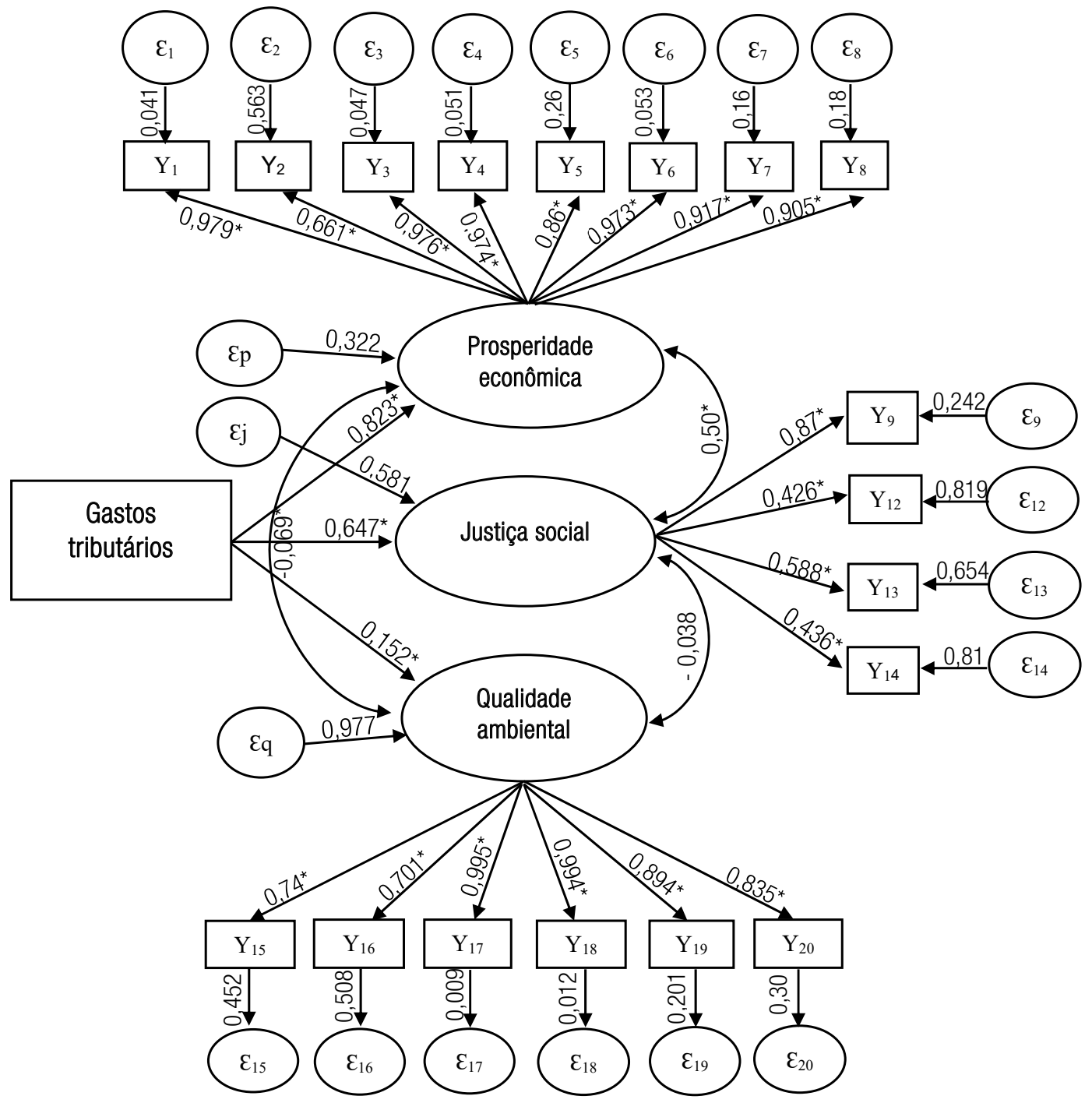

Nota: $\left({ }^{*}\right.$ ) Relação estatística com 95\% de confiabilidade, considerando o nível de significância de 5\% (Barbetta, 2012). Fonte: Elaborada pelos autores. 
Conforme se constata na Figura 2, a relação entre a variável "gastos tributários" e o construto "prosperidade econômica" apresenta significância estatística e coeficiente elevado $(0,823)$. No que tange à variável "gastos tributários" e ao construto "justiça social”, a relação também apresenta significância estatística, porém o coeficiente $(0,647)$ é inferior àquele verificado na relação entre "gastos tributários e "prosperidade econômica" (0,823). Quanto à relação entre a variável "gastos tributários" e o construto "qualidade ambiental", apesar de apresentar significância estatística, o coeficiente é baixo $(0,152)$, principalmente se comparado àqueles obtidos nas relações entre "gastos tributários" e "prosperidade econômica" $(0,823)$, bem como entre "gastos tributários" e "justiça social" $(0,647)$.

Esses resultados, portanto, indicam que os gastos tributários estão mais ligados à dimensão econômica da sustentabilidade municipal (Ministério da Economia, 2019; Soares, Gomes \& Toledo, 2011), podendo-se inferir que a concessão de benefícios fiscais de ICMS - por meio da atração e da manutenção de empreendimentos - movimenta a economia local, o que corrobora os achados de Botelho et al. (2019), Chicumbi (2018), Klemm e Parys (2012), Rezende et al. (2018) e Rezende et al. (2019). Assim, confirma-se a hipótese $\mathrm{H}_{1}$ (“Os gastos tributários de ICMS se relacionam, positivamente, com a prosperidade econômica dos municípios catarinenses").

Em contrapartida, os resultados apontam também que os gastos tributários influenciam de forma secundária na dimensão social e pouco influenciam na dimensão ambiental. Em relação à dimensão social, os resultados corroboram os achados de Accordino (2020), Killian e O'Regan (2018), sugerindo ao mesmo tempo a regressividade dos impostos indiretos, como o ICMS (OCDE, 2020; Oliveira \& Chieza, 2018), além de apontarem a necessidade de uma reforma tributária (Appy et al., 2020; ONU, 2015). Quanto à dimensão ambiental, os resultados contrariam os achados de He et al. (2019) e Killian e O’Regan (2018), assim como as constatações de Trennepohl (2011) e Moura (2015), de que a extrafiscalidade no âmbito de ICMS tem sido muito utilizada para fins ambientais. Esses resultados divergentes podem se dar pelo fato de o ICMS Ecológico ainda não ter sido implementado em Santa Catarina. Faz-se necessária, portanto, a adoção, por parte do Estado, de uma visão mais holística - e menos econômica - no que tange aos critérios utilizados na concessão de benefícios fiscais de ICMS, especialmente diante das atuais alterações climáticas e da devastação do meio ambiente, que colocam em risco a própria sobrevivência da civilização (I. Sachs, 2008; J. Sachs, 2017). De todo modo, confirmam-se as hipóteses $\mathrm{H}_{2}$ ("Os gastos tributários de ICMS se relacionam, positivamente, com a justiça social dos municípios catarinenses") e $\mathrm{H}_{3}$ (“Os gastos tributários de ICMS se relacionam, positivamente, com a qualidade ambiental dos municípios catarinenses”).

Ainda na Figura 2, observa-se que as variáveis que compõem o construto "prosperidade econômica" têm significância estatística e que a maioria dos coeficientes é elevada, sendo a variável $\mathrm{Y}_{1}$ ("valor adicionado bruto") a de maior coeficiente $(0,979)$, e a variável $Y_{2}$ ("consumo de energia" $[0,661]$ ), a de menor. Destacam-se os coeficientes elevados das variáveis $\mathrm{Y}_{1}$ ("valor adicionado bruto") e $\mathrm{Y}_{8}$ ("arrecadação com o ICMS”), considerando que o movimento econômico é a principal variável no cálculo do rateio constitucional de ICMS. Esse resultado corrobora os achados de Rezende et al. (2019), isto é, os benefícios fiscais de ICMS contribuem para o incremento na arrecadação desse imposto e para seu repasse constitucional ao município.

Ainda observando a Figura 2, constata-se que todas as variáveis que compõem o construto “justiça social” têm significância estatística, porém apenas a variável $Y_{9}$ ("número de óbitos") apresenta coeficiente elevado $(0,87)$, enquanto a $\mathrm{Y}_{12}$ (“Índice Firjan de Desenvolvimento Municipal 
de Emprego e Renda" [0,426]) apresenta o menor coeficiente. Quanto às variáveis que compõem o construto "qualidade ambiental", elas têm significância estatística, e a maioria dos coeficientes é elevado, com a variável $Y_{17}$ ("garantia de saúde pública” [0,995]) apresentando o maior coeficiente, e $\mathrm{Y}_{16}$ ("drenagem urbana e manejo de águas pluviais" [0,701]), o menor. Os resultados obtidos nas variáveis $\mathrm{Y}_{18}$ ("abastecimento de água" $\left.[0,994]\right)$ e $\mathrm{Y}_{19}$ ("esgotamento sanitário $[0,894]$ ) corroboram os achados de Soares e Almeida (2018), os quais concluíram que o crescimento econômico tem sido acompanhado por melhorias nas dimensões água e saneamento.

Por fim, no que se refere às covariâncias, os resultados (Figura 2) apontam significância estatística e coeficiente moderado $(0,50)$ entre os construtos "prosperidade econômica" e "justiça social". Esse resultado está em consonância com o fato de a Constituição Federal de 1988 delegar aos municípios a prestação de serviços essenciais à população local, os quais exigem aporte substancial de recursos financeiros (Buissa et al., 2017; Gomes et al., 2020). De forma oposta, os resultados da covariância entre os construtos “justiça social e "qualidade ambiental” não apontam significância estatística e revelam coeficiente baixo $(-0,038)$. Da mesma forma, a covariância entre os construtos "prosperidade econômica e "qualidade ambiental", apesar de os resultados apontarem significância estatística, o coeficiente também é baixo $(-0,069)$. Esses resultados podem ser explicados com base nos achados de Zhou et al (2014), os quais concluem que os países em desenvolvimento, até atingirem determinado nível de renda, crescem sem se preocupar com a qualidade do meio ambiente.

\section{CONSIDERAÇÕES FINAIS}

As pesquisas que vêm sendo realizadas sobre os efeitos dos benefícios fiscais, de modo geral, não analisam as dimensões da sustentabilidade de forma integrada, enfatizando principalmente a dimensão econômica e, de maneira secundária, as dimensões social e ambiental, limitando-se a discutir argumentos técnicos ou jurídicos, os quais, apesar de importantes, não mensuram os impactos dos gastos tributários.

Neste artigo, portanto, buscou-se abordar a questão dos benefícios fiscais de ICMS e sua influência na sustentabilidade dos atuais 295 municípios catarinenses, com base nos conceitos de gasto tributário e do TBL, representado pelas dimensões da prosperidade econômica, da justiça social e da qualidade ambiental.

Para tanto, partindo da tese de que os benefícios fiscais de ICMS influenciam positivamente na sustentabilidade dos municípios catarinenses e da concepção de que os gastos tributários devem se sujeitar à avaliação multidimensional de sustentabilidade de impactos, elaborou-se um conjunto de dados secundários em painel, coletados entre 2005 e 2017, os quais foram analisados por meio da técnica de MEE generalizada.

Feito isso, apesar de os resultados apontarem relações estatisticamente significativas, conclui-se que os gastos tributários promovem, em grau elevado, a sustentabilidade econômica; em grau moderado, a sustentabilidade social; e, em grau baixo, a sustentabilidade ambiental. Por conseguinte, indicam ainda que a concessão de benefícios fiscais de ICMS em Santa Catarina privilegia os aspectos econômicos e que, no caso do meio ambiente, o Poder Público estadual pouco investe na extrafiscalidade tributária visando amenizar os efeitos deletérios do aquecimento global e da devastação ambiental. Cabe aqui lembrar que este estudo se limitou à análise do impacto dos benefícios fiscais no âmbito do estado de Santa Catarina, ou seja, não levou em consideração os efeitos dessa política tributária catarinense sobre os demais estados e municípios brasileiros. 
Assim, ante as análises apresentadas até aqui, confirma-se a urgência de que as administrações tributárias, de todos os níveis, avaliem, sob a óptica de multidimensionalidade, os atuais métodos empregados na mensuração das renúncias fiscais e os impactos e as efetividades dos gastos tributários para a sustentabilidade da União, dos estados e dos municípios.

Sobre o método desenvolvido - que pode ser adaptado a outros tributos e benefícios fiscais - e os resultados obtidos nesta pesquisa, considera-se que são relevantes aos gestores públicos, pois, ao clarificar os efeitos dos gastos tributários sob uma perspectiva de macrodesenvolvimento, auxiliam os tomadores de decisão diante de complexos e difíceis trade-offs, como arrecadar tributos versus atrair ou manter empresas em seus territórios. Ademais, o método de modelagem estatística aplicado neste estudo pode ser empregado em todas as unidades da federação, inclusive na própria União, uma vez que os profissionais das administrações tributárias, de todos os níveis de governo, poderão adotá-lo, inclusive aprimorando-o ou adaptando-o às suas circunstâncias específicas.

Considerando a imprescindibilidade de o sistema tributário nacional responder à avaliação multidimensional de sustentabilidade dos impactos, incorporando definitivamente o princípio da sustentabilidade (Freitas, 2016), esta pesquisa contribui para o avanço do conhecimento nos campos da extrafiscalidade tributária e do desenvolvimento sustentável, posto que os estudos sobre os impactos dos benefícios fiscais, em geral, orbitam nas discussões de cunho jurídico. Quando muito, tais estudos empregam estatística descritiva para tentar mensurar os efeitos dos benefícios fiscais na esfera econômica ou empresarial, sem considerar de forma integrada as dimensões econômica, social e ambiental. Além disso, como observa Alhaddi (2015), a literatura tem apresentado um emprego inconsistente do termo "sustentabilidade", considerando que vários estudos, ao o utilizarem, referemse apenas a uma ou duas de suas dimensões.

Em síntese, pode-se afirmar que o objetivo deste artigo foi alcançado, visto que, com base nos resultados obtidos na aplicação da MEE, restou demonstrada, de forma teórica e empírica, a influência dos benefícios fiscais de ICMS na sustentabilidade econômica, social e ambiental dos municípios catarinenses.

Quanto às limitações do método desenvolvido, destaca-se a existência de dados dicotômicos e com valores omissos, que gerou o problema da não concavidade do modelo. Além disso, as séries temporais anuais ficaram limitadas aos anos de 2005 a 2017, período que pode ser considerado curto no atual contexto de rápidas mudanças econômicas, sociais e ambientais.

Para estudos futuros, sugere-se a análise do impacto dos benefícios fiscais de ICMS por segmento ou atividade econômica, investigando-se, num estudo comparativo, por quanto tempo os gastos tributários repercutem na economia. Nesse caso, sugere-se o uso de variáveis abrangendo todos os estados, o que possibilitará verificar o impacto mútuo das desonerações tributárias nas diversas unidades da federação. Incentiva-se também a realização de estudos baseados na proposta de reforma tributária (PEC 45, 2019), que prevê a substituição de cinco impostos incidentes sobre o consumo, incluindo o ICMS, pelo IBS, o qual teria finalidade essencialmente arrecadatória, com a ausência de caráter extrafiscal. 


\section{REFERÊNCIAS}

Abraham, M. (2019). Reflexões sobre finanças públicas e direito financeiro. Salvador, BA: JusPodivm.

Accordino, P. (2020). Fiscal Policy for Sustainable Development: The Italian Way to Promote Innovative Entrepreneurship According to European Union Rules. In V. Mauerhofer, D. Rupo, \& L. Tarquinio (Eds.), Sustainability and Law: General and Specific Aspects (pp. 201-219). Geneva, Switzerland: Springer Nature.

Afonso, J. R. R. (2014). A renúncia tributária do ICMS no Brasil. Washington, DC: Banco Interamericano de Desenvolvimento (BID).

Alhaddi, H. (2015). Triple Bottom Line and Sustainability: A Literature Review. Business and Management Studies, 1(2), 6-10.

Appy, B., Santi, E., Coelho, I., Machado, N., \& Canado, V. R. (2020). Tributação no Brasil: o que está errado e como consertar? In N. Yoshiaki (Org.), Brasil sob reforma. Rio de Janeiro, RJ: FGV.

Aranha, F., \& Zambaldi, F. (2008). Análise fatorial em administração. São Paulo, SP: Cengage Learning.

Armbruster, S., \& Hintermann. B. (2020). Decentralization with porous borders: public production in a federation with tax competition and spillovers. International Tax and Public Finance, 27, 606-642.

Balthazar, U. C. (2008). A gênese do imposto sobre o valor agregado. Revista Sequência, 56, 245-258.

Barbetta, P. A. (2012). Estatística aplicada às ciências sociais. Florianópolis, SC: Editora da Ufsc.

Bertolai, J. D. P. (2009). Dinâmica monetária eficiente sob encontros aleatórios: uma classe de métodos numéricos que exploram concavidade (Dissertação de Mestrado). Fundação Getulio Vargas, Rio de Janeiro, RJ.

Bido, D. S., Silva, D., Souza, C. A., \& Godoy, A. S. (2010). Mensuração com indicadores formativos nas pesquisas em administração de empresas: como lidar com a multicolinearidade entre eles? Administração - Ensino e Pesquisa, 11(2), 245-269.

Bomfim, P. R. C. M., Almeida, R. S., Gouveia, V. A. L., Macedo, M. A. S., \& Marques, J. A. V. C. (2011). Utilização de análise multivariada na avaliação do desempenho econômico-financeiro de curto prazo: uma aplicação no setor de distribuição de energia elétrica. Revista Adm.Made, 15(1), 75-92.

Botelho, L. H. F., Abrantes, L. A., \& Fialho, N. S. (2019). Reflexões sobre as aplicações de políticas de desonerações tributárias no desenvolvimento regional brasileiro. Cadernos Gestão Pública e Cidadania, 24(79), 1-20.

Brandão, S. C., Jr. (2014). Federalismo e ICMS: Estados-membros em "guerra fiscal". São Paulo, SP: Quartier Latin.

Buissa, L., Bevilacqua, L., \& Morais, P. H. (2017). Incentivos fiscais de ICMS e renúncia de receita com o Regime de Recuperação Fiscal (RRF). Revista Fórum de Direito Financeiro e Econômico (RFDFE), 6(11), 127-143.

Caldeira, E., Geourjon, A-M., \& Rota-Graziosi. G. (2020). Taxing aid: the end of a paradox? International Tax and Public Finance, 27, 240-255.

Caliendo, P. (2013). Limitações constitucionais ao poder de tributar com finalidade extrafiscal. Revista do Programa de Pós-Graduação em Direito da Universidade Federal do Ceará, 33(2), 171-206.

Carrazza, R. A. (2015). ICMS. São Paulo, SP: Malheiros.

Cavalcante, D. L. (2012). Tributação ambiental: por uma remodelação ecológica dos tributos. Revista Nomos, 32(2), 101-115.

Cavalcante, D. L. (2017). A (in) sustentabilidade do atual modelo de incentivos fiscais com fins ambientais. In Anais do $14^{\circ}$ Congresso Nacional de Estudos Tributários do Instituto Brasileiro de Estudos Tributários, São Paulo, SP.

Chicumbi, J. P. N. (2018). Os benefícios fiscais do imposto industrial à economia angolana: estudos de caso dos municípios e da catumbela (Dissertação de Mestrado). Universidade Portucalense Infante D. Henrique, Porto, Portugal.

Constituição da República Federativa do Brasil, de 5 de outubro de 1988. (1988). Brasília, DF.

Correia, C. B., Neto. (2016). O avesso do tributo: incentivos e renúncias fiscais no direito brasileiro. São Paulo, SP: Almedina.

Daros, L. L., \& Secchi, L. (2013). Jogos não cooperativos e a guerra fiscal entre os estados pelo 
ICMS da importação: uma análise com enfoque no equilíbrio de Nash. In Anais do $37^{\circ}$ Encontro da Anpad, Rio de Janeiro, RJ.

Decreto $n^{\circ} 7.2017$, de 21 de julho de 2010. (2010). Regulamenta a Lei $\mathrm{n}^{\circ} 11.445$, de 5 de janeiro de 2007, que estabelece diretrizes nacionais para o saneamento básico. Brasília, DF.

Elkington, J. (1998). Accounting for the triple bottom line. Measuring Business Excellence, 2(3), 18-22.

Elkington, J. (2020). Green swans: the coming boom in regenerative capitalism. New York, NY: Fast Company Press.

Fávero, L. P. L. (2013). Dados em painel em contabilidade e finanças: teoria e aplicação. Brazilian Business Review, 10(1), 131-156.

Fávero, L. P. L, \& Belfiore, P. (2017). Manual de análise de dados. Rio de Janeiro, RJ: Elsevier.

Feld, L. P., Köhler, E. A., \& Wolfinger, J. (2020). Modeling fiscal sustainability in dynamic macropanels with heterogeneous effects: evidence from German federal states. International Tax and Public Finance, 27, 215-239.

Figueiredo, D. B. F., \& Silva, J. A., Jr. (2010). Visão além do alcance: uma introdução à análise fatorial. Opinião Pública, 16(1), 160-185.

Freitas, J. (2016). O tributo e o desenvolvimento sustentável. Revista Novos Estudos Jurídicos, 21(3), 825-845.

Gobetti, S. W., \& Orair, R. O. (2017). Resultado primário e contabilidade criativa: reconstruindo as estatísticas fiscais "acima da linha" do governo geral (Working Paper no 2288). Brasília, DF: Instituto de Pesquisa Econômica Aplicada.

Gomes, R. C., Osborne, S.P., \& Guarnieri, P. (2020). Influências dos stakeholders e desempenho do governo local: uma revisão sistemática da literatura. Revista da Administração Pública, 54(3), 448-467.

Hair, J. F., Jr., Black, W. C., Babin B. J., Anderson, R. E., \& Tatham, R. L. (2009). Análise multivariada de dados. Porto Alegre, RS: Bookman.

Hall, J. L., \& Kanaan, D. Z. (2020). State Tax Policy, Municipal Choice, and Local Economic Development Outcomes: A Structural Equation Modeling Approach to Performance Assessment.
Public Administration Review. Recuperado de https://doi.org/10.1111/puar.13165

He, P., Zhang, Y., Yuan, Y., Qiao, Y., Xin, L., \& Zou, X. (2019). The Relationship between Environmental Taxation, Environmental Performance and Economic Growth: Comparative Study of Sweden and China 1985-2016. Ekoloji, 28(107), 401-410.

Instituto Brasileiro de Geografia e Estatística. (2015). Indicadores de Desenvolvimento Sustentável. Rio de Janeiro, RJ: IBGE.

Isil, O., \& Hernke, M. T. (2017). The Triple Bottom Line: A Critical Review from a Transdisciplinary Perspective. Business Strategy and the Environment, 28(8), 1235-1251.

Kalambokidis, L. (2014). Creating Public Value with Tax and Spending Policies: The View from Public Economics. Public Administration Review, 74(4), 519-526.

Kasdin. S. (2018). Budgeting Rules and Program Outcomes. Public Administration Review, 78(5), 759-771.

Killian, S., \& O’Regan, P. (2018). Taxation and Social Enterprise: Constraint or Incentive for the Common Good. Journal of Social Entrepreneurship, 10(1), 1-18.

Kleinbard, E. D. (2010). Tax expenditure framework legislation. National Tax Journal, 63(2), 353-382.

Klemm, A., \& Parys, S. V. (2012). Empirical evidence on the effects of tax incentives. International Tax and Public Finance, 19, 393-423.

Kline, R. B. (2016). Principles and practice of structural equation modeling. New York, NY: Guilford.

Lei Complementar $n^{\circ}$ 160, de 7 de agosto de 2017. (2017). Dispõe sobre convênio que permite aos estados e ao Distrito Federal deliberar sobre a remissão dos créditos tributários e a reinstituição de isenções, incentivos e benefícios fiscais ou financeiro-fiscais. Brasília, DF.

Lei $n^{\circ} 12.305$, de 2 de agosto de 2010. (2010). Institui a Política Nacional de Resíduos Sólidos. Brasília, DF.

Lei $n^{\circ}$ 17.566, de 7 de agosto de 2019. (2019). Dispõe sobre as diretrizes orçamentárias para o exercício financeiro de 2019. Florianópolis, SC. 
Lester, J. (2017). Reviewing federal tax expenditures. Canadian Tax Foundation, Income Tax at 100 years, 17(1), 1-36.

Macedo, F. C., \& Angelis, A. (2013). Guerra fiscal dos portos e desenvolvimento regional no Brasil. Revista de Desenvolvimento Regional, 18(1), 185-212.

Malheiros, T. F., Coutinho, S. M. V., \& Philippi, A., Jr. (2012). Indicadores de sustentabilidade: uma abordagem conceitual. In A. Philippi, Jr., \& T. F. Malheiros (Coords.), Indicadores de sustentabilidade e gestão ambiental. Barueri, SP: Manole.

Marôco, J. (2014). Análise de equações estruturais: fundamentos teóricos, software e aplicações. Pêro Pinheiro, Portugal: ReportNumber Lda.

Mélo, L. G. G., \& Oliveira, P. D., Netto. (2019). Os desafios para alcançar a sustentabilidade do Estado fiscal em período de crise econômica. Revista Jurídica, 1(54), 481-498.

Ministério da Economia (2019). Secretaria de Avaliação, Planejamento, Energia e Loteria (Secap). Boletim mensal sobre os subsídios da União: distribuição regional dos gastos tributários. Brasília, DF: Autor.

Moura, A. S. (2015). Imposto sobre circulação de mercadorias e serviços socioambiental: incentivos institucionais e legislação ambiental no Brasil. Revista da Administração Pública, 49(1), 165-187.

Nascimento, S. D. (2008). Guerra fiscal: uma avaliação comparativa entre alguns estados participantes. Economia Aplicada, 12(4), 677-706.

Nobre, F. S., \& Ribeiro, R. E. M. (2013). Cognição e sustentabilidade: estudo de casos múltiplos no índice de sustentabilidade empresarial da BM\&FBovespa. Revista de Administração Contemporânea, 17(4), 499-517.

Oliveira, F. A., \& Chieza, R. A. (2018). Auge e declínio da federação brasileira: 1988-2017. In Associação Nacional dos Auditores-Fiscais da Receita Federal do Brasil, \& Federação Nacional do Fisco Estadual e Distrital (Eds.), A Reforma Tributária necessária: diagnóstico e premissas. São Paulo, SP: Plataforma Política Social.

Oliveira, L. M. V. S. (2015). Declaração de inconstitucionalidade de benefício fiscal de ICMS concedidosem prévio convênio Confaze consequências práticas. Revista Jurídica da Procuradoria-Geral do Distrito Federal, 40(1), 135-164.

Organização das Nações Unidas. (2015). Transforming our world: the 2030 Agenda for Sustainable Development. New York, NY: ONU.

Organização para a Cooperação e o Desenvolvimento Econômico. (2020). Tax Policy Reforms 2020: OECD and Selected Partner Economies. Paris, France: OCDE.

Organização para a Cooperação e o Desenvolvimento Econômico, Organização das Nações Unidas, Centro Interamericano de Administrações Tributárias, \& Banco Interamericano de Desenvolvimento. (2020). Revenue Statistics in Latin America and the Caribbean: 1990-2018. Paris, France: OCDE.

Parys, S. V., \& James, S. (2010). The effectiveness of tax incentives in attracting investment: panel data evidence from the CFA Franc zone. International Tax and Public Finance, 17, 400-429.

Pellegrini, J. A. (2014). Gastos tributários: conceitos, experiência internacional e o caso do Brasil. Brasília, DF: Núcleo de Estudos e Pesquisas do Senado Federal.

Porter, M. E. (1989). A vantagem competitiva das nações. Rio de Janeiro, RJ: Campus.

Porto, G. S., \& Memória, C. V. (2019). Incentivos para inovação tecnológica: um estudo da política pública de renúncia fiscal no Brasil. Revista de Administração Pública, 53(3), 520-541.

Prado, P. H. M. (2006). Os modelos de equações estruturais em marketing. In D. Botelho, \& D. M. Zouain (Orgs.), Pesquisa Quantitativa em Administração. Rio de Janeiro, RJ: Atlas.

Proposta de Emenda à Constituição no 45, de 3 de abril de 2019. (2019). Altera o Sistema Tributário Nacional. Brasília, DF.

Qi, Y., Peng, W., \& Xiong, N. N. (2020). The Effects of Fiscal and Tax Incentives on Regional Innovation Capability: Text Extraction Based on Python. Mathematics, 8(7), 1-19.

Receita Federal do Brasil. (2018). Demonstrativo dos Gastos Tributários (PLOA 2019). Brasília, DF.

Redonda, A. (2016). Tax Expenditures and Sustainability: An Overview. Discussion Note. Zurich, Switzerland: Council on Economic Policies. 
Rezende, A. J., Dalmácio, F. Z., \& Rathke, A. A. T. (2018). Avaliação dos impactos dos incentivos fiscais sobre os retornos e as políticas de investimentos e financiamento das empresas. Revista Universo Contábil, 14(4), 28-49.

Rezende, E., Peralta, R., Rosa, L. P., \& Rezende, A. J. (2019). Análise do custo fiscal efetivo das renúncias fiscais estaduais. Tax and Accounting Studies, 1(24), 1-20.

Rezende, R. O. (2020). Benefícios e competição fiscal entre estados brasileiros: judicialização da "Guerra Fiscal" do ICMS no Supremo Tribunal Federal. Revista Cadernos de Finanças Públicas, 1(1), 1-80.

Sá, D., \& Silva, M. V. G. (2019). O papel do Estado no processo de formação industrial: o caso da região metropolitana de Curitiba. Revista Brasileira de Estudos Urbanos e Regionais, 21(1), 189-202.

Sachs, I. (2008). Desenvolvimento: includente, sustentável, sustentado. Rio de Janeiro, RJ: Garamond.

Sachs, J. D. (2017). A era do desenvolvimento sustentável. Lisboa, Portugal: Conjuntura Actual.

Sampieri, R. H., Collado, C. F., \& Lucio, M. P. B. (2013). Metodologia de pesquisa. Porto Alegre, RS: Penso.

Schumacker, R. E., \& Lomax, R. G. (2016). A beginner's guide to structural equation modeling. New York, NY: Routledge.

Silva, J. F. B. A., Rebouças, S. M. D. P., Abreu, M. C. A., \& Ribeiro, M. C. R. (2018). Construção de um índice de desenvolvimento sustentável e análise espacial das desigualdades nos municípios cearenses. Revista de Administração Pública, 52(1), 149-168.
Soares, L. R., \& Almeida, L. T. (2018). Desacoplamento de impactos ambientais no Brasil. Revista Iberoamericana de Economía Ecológica, 28(2), 21-43.

Soares, M., Gomes, E. C. O., \& Toledo, J. R., F. (2011). A repartição tributária dos recursos do ICMS nos municípios da Região Metropolitana de Curitiba. Revista de Administração Pública, 45(2), 459-481.

Sunstein, C. R. (2014). O mundo real da análise de custo-benefício: 36 questões (e quase tantas respostas quanto). Revista de Direito Administrativo, $266,13-47$.

Surrey, S. S. (1970). Tax incentives as a device for implementing government policy: a comparison with direct government expenditures. Harvard Law Review, 83(40), 705-738.

Teodósio, A. S. S., Dias, S. F. L. G., \& Santos, M. C. L. (2016). Procrastinação da política nacional de resíduos sólidos: catadores, governos e empresas na governança urbana. Ciência e Cultura, 68(4), 30-35.

Trennepohl, T. D. (2011). Incentivos fiscais no Direito Ambiental. São Paulo, SP: Saraiva.

Ufier, A. (2017). The effect of VATs on government balance sheets. International Tax and Public Finance, 24, 1141-1173.

Wedy, G. (2018). Desenvolvimento sustentável na era das mudanças climáticas: um direito fundamental. São Paulo, SP: Saraiva.

Zhou, Z. Y., Liu, H., \& Cao, L. (2014). Food consumption in China: the revolution continues. Northampton, Massachusetts: Edward Elgar Publishing. 


\section{Amery Moisés Nadir Junior}

https://orcid.org/0000-0001-7339-2285

Doutor em Administração; Auditor fiscal da Receita Estadual. E-mail: amerymnj@gmail.com

\section{Anete Alberton}

https://orcid.org/0000-0002-6477-0122

Doutora em Engenharia de Produção; Professora permanente do Programa de Pós-Graduação em Administração da Universidade do Vale do Itajaí (PPGA/Univali). E-mail: anete@univali.br

\section{Kleverton Clóvis de Oliveira Saath}

https://orcid.org/0000-0001-6862-9030

Mestre em Economia; Consultor de treinamento para empresas. E-mail: klevertonsaath@gmail.com 